\title{
Does It Pay to Play? How Bargaining Shapes Donor Participation in the Funding of Environmental Protection*
}

\author{
Patrick Bayer $^{\dagger}$ \\ University of Mannheim \\ Johannes Urpelainen \\ Columbia University
}

14 December 2013

\begin{abstract}
Multilateral funding for global environmental protection, such as biodiversity conservation, requires donor participation. When are donors willing to participate? We examine a game-theoretic model of multilateral funding for environmental projects in developing countries. Donors must first decide whether to participate in a multilateral institution. They do so in anticipation of a bargaining outcome that depends on their participation decisions. The multilateral institution then bargains with a recipient over the distribution of gains from project implementation. We find that the donors' and the recipient's vulnerability to negative environmental externalities have diverging effects on their participation behavior. As donors' vulnerability to negative externalities increases, their bargaining power decreases and fewer donors participate. But as the recipient's vulnerability increases, more donors participate because their bargaining power grows. These findings can illuminate bargaining over multilateral climate finance and inform the design of international institutions.
\end{abstract}

\footnotetext{
*This paper was written during a research stay funded by an ERP fellowship of the Studienstiftung des deutschen Volkes. Patrick Bayer gratefully acknowledges this generous funding and is thankful for the hospitality of Columbia University. We thank Christopher Marcoux, Michael Rubin, Ariel Dinar, and the reviewers for insightful comments on a previous draft. An online appendix contains model extensions and technical details.

${ }^{\dagger}$ Corresponding author. Department of Political Science, University of Mannheim, D7, 27, 68131 Mannheim, Germany. Phone: + 49621181 2418. Email: pbayer@mail.uni-mannheim.de
} 


\section{Introduction}

If multilateral institutions are to fund environmental protection, such as biodiversity conservation, two conditions must be met. First, donors must participate in the funding program. Second, the participating donors must successfully bargain with recipient countries over the distribution of gains. While Gatti et al. (2011: 611) provide an insightful discussion of biodiversity bargaining between a "technology-rich North and a gene-rich South," we highlight that understanding bargaining is difficult when ignoring participation, and vice versa. The expected outcome of donor-recipient bargaining influences donors' prior decisions to participate. The number of participating donors influences the bargaining outcome. Analyses of bargaining are misleading when they fail to account for the strategically prior participation problem, and analyses of participation are misleading when they fail to account for the subsequent bargaining stage.

Consider Ecuador's promise to leave about $20 \%$ of its national oil resources, found under the Yasuní National Park, untapped to protect biodiversity. In exchange for preserving one of the world's most biodiverse regions, Ecuador demanded US\$ 3.6 billion from a group of international donors as compensation. ${ }^{1}$ Highlighting the importance of bargaining and participation, it was initially unclear if enough governments were willing to participate in the Yasuní initiative to meet the US\$350 million target in required annual funding, even after Germany and Spain committed to jointly earmark US\$ 70 million in September 2009 (Martin, 2011). By October 2013, however, it became clear that the scheme had failed. Donors never participated in the effort, and the Ecuadorian parliament approved the beginning of drilling. ${ }^{2}$ The North-South game of biodiversity conservation never reached the bargaining stage, as donors refused to participate.

Explaining variation in the provision of environmental assistance has recently been a central aim of research. While previous research - starting with early contributions by Carraro and Siniscalco (1993), Barrett (1994b), and Hoel (1992) - has recognized the participation problem and examined bilateral donorrecipient bargaining (Gatti et al., 2011), the literature has not yet combined these elements. Empirically, the relationship between participation and bargaining is a timely topic. As documented below, donors have recently started to shift their emphasis from multilateral to bilateral funding of environmental projects. This

\footnotetext{
1،Ecuador Pledges No Oil Drilling in Amazon Reserve." BBC News, August 3, 2010. Accessed on November 6, 2013. See http://www.bbc.co.uk/news/world-latin-america-10861415.

2"Ecuador Allows Drilling in Yasuni National Park." Deutsche Welle, October 4, 2013. Accessed on November 7, 2013. See http://www.dw.de/ecuador-allows-drilling-in-yasuni-national-park/a-17134585.
} 
form of non-participation in multilateral institutions is surprising, given that many environmental projects generate global benefits. As shown below, our model can illuminate the reasons for this shift.

We examine a game-theoretic model of multilateral funding for environmental projects that eradicate negative externalities. Donors must first decide whether to participate in a multilateral institution. Participation in the institution can be given two interpretations. On the one hand, donors can participate in an $a d$ hoc trust fund to solve a specific problem. On the other hand, donors can decide on participation in a more permanent multilateral institution. This multilateral institution then bargains with a single recipient over the distribution of gains from project implementation. In the ad hoc case, the bargaining focuses on a specific project. In the formation of a more permanent institution, the bargaining stage focuses on a representative project. Successfully implemented projects not only eradicate international negative externalities (global public goods) but also produce value for both the donors and the recipient (club goods), with interesting implications, as shown by Finus and Rübbelke (2013). In the bargaining game, the multilateral institution and the recipient distribute the joint gains from implementing the project between them. Such bargaining features both side payments and negotiations over the terms of implementation.

Although the model assumes a zone of agreement exists in bargaining, countries generally fail to reap full gains from global public goods because donors have strategic incentives to refrain from participation. This main result is stark. Even if bargaining is assumed to be efficient, as is done here, participation failure undermines the provision of global public goods. While the extant literature has studied how uncertainty and learning (Na and Shin, 1998; Kolstad and Ulph, 2011), country asymmetries (McGinty, 2007), side payments (Hoel and Schneider, 1997; Barrett, 2001), different technology types (Hoel and Zeeuw, 2010; Barrett, 2006, 2012), pollutant characteristics (Ulph, 2004), climate irreversibilities (Ulph and Ulph, 1997), and dynamic time effects (de Zeeuw, 2008; Rubio and Ulph, 2007) shape participation incentives, most models fail to discuss the distribution of ex post payoffs once participation decisions are taken.

By explicitly modeling bargaining after a strategically prior participation stage, we can derive comparative statics as to how donor and recipient characteristics in bargaining affect participation in the first place. A heterogeneous effect of the donors' and the recipient's vulnerability on participation. As the donors' vulnerability to negative externalities increases, their outside option in case of bargaining failure weakens, and this reduces their bargaining power. Thus, fewer donors are willing to participate. However, as the 
recipient's vulnerability to negative externalities increases, more donors participate because their bargaining power grows. Curiously, this may ultimately benefit the recipient due to a greater availability of club goods.

According to previous research, large global benefits of international cooperation paradoxically deter participation in multilateral environmental cooperation (Barrett, 2003; Finus, 2008). This result must be qualified when bargaining concerns are central. Specifically, it holds for donors but not for recipients. When donors fund global public goods that they value a lot, participation is difficult to attain. But if recipients also value these global public goods - even if not enough to fund without external assistance - then participation is easy to attain. Donors' bargaining power increases because the recipient's dependence on project implementation increases, so more donors are willing to participate. This result holds because the recipient's bargaining power influences donors' strategic incentives to participate, and it holds regardless of the availability of club goods from project implementation.

For policy analysis, it is important to note that discriminatory arrangements producing club goods for participating donors and the recipient can improve donor participation, and thus increase global welfare. If participating donors are given rents that outsiders cannot obtain, the number of participating donors can be increased. This insight contrasts with recent findings by Finus and Rübbelke (2013) and underscores the importance of accounting for strategic implications on participation from bargaining.

\section{Environmental Protection, Negative Externalities, and Multilateral Insti- tutions}

We define global public goods as projects that produce non-rival and non-excludable benefits for a large number of different countries around the world (Anand, 2004: 216). The distinctive feature of global public goods is the diffuse nature of the benefits that they produce (Barrett, 2007; Kaul, Grunberg, and Stern, 1999;

Sandler, 2004). While countries may differ in their valuation of any given global public good, a large number of countries nonetheless benefits from it.

We focus on global public goods that eradicate negative externalities from environmental deterioration. A project is an effort to reduce the generation of negative environmental externalities from a recipient country. Examples include climate mitigation (Fischer and Newell, 2008; Finus, Kotsogiannis, and McCorriston, 
2013), biodiversity conservation (Goeschl and Swanson, 2002; Gatti et al., 2011), and protection of fisheries (Underdal, 1980). Our interest is in multilateral strategies for the funding of environmental protection. Multilateral institutions are rules and procedures that allow groups of countries to coordinate their policies (Ruggie, 1992). They can be either trust funds focused on a specific problem or a more permanent solution that addresses multiple problems over time. Since global public goods produce collective benefits, multilateral institutions hold promise for the provision of these goods (Kaul, Grunberg, and Stern, 1999).

The participation problem has been analyzed in the context of multilateral environmental agreements. When cooperation is useful, only small coalitions can be sustained in equilibrium (Barrett, 1994b). In recent years, this baseline model has been extended in multiple directions. Relaxing the assumption of complete information, Na and Shin (1998) show that better information about ex post benefits makes international cooperation more difficult, thereby highlighting the negative social value that better scientific knowledge may have - a finding that is echoed for systematic uncertainty about a common payoff parameter (Kolstad, 2007; Kolstad and Ulph, 2008) as well as distributional uncertainty that allows for ex post heterogeneity in payoffs (Kolstad and Ulph, 2011; Finus and Pintassilgo, 2012).

Other extensions pertain to the effect of technological innovation (Hoel and Zeeuw, 2010; Barrett, 2006, 2012), side payments (Hoel and Schneider, 1997; Barrett, 2001), and sanctions (Barrett, 1997) on participation in multilateral treaties. These models show that cooperation becomes sustainable once the participation problem can be turned into a coordination problem. Rubio and Ulph (2007) and de Zeeuw (2008) present dynamic accounts of the coalition formation game, allowing coalition sizes and abatement patterns to change endogenously over time. Ulph and Maddison (1997) use a dynamic two-period model to examine the effect of stock pollutants, such as greenhouse gases.

The almost exclusive focus on participation comes at a cost of bargaining. Only recently, scholars have started to study how bargaining affects environmental cooperation. For example, Caparrós and Péreau (2013) examine the implications of coalition formation for bargaining in North-South climate agreements and Gatti et al. (2011) analyze bargaining for biodiversity conservation. In contrast to our contribution, these recent works miss the opportunity to link bargaining with non-cooperative participation incentives. In Gatti et al.'s (2011) model, the South's threat of strategic destruction of valuable biodiversity is credible and increases the South's bargaining power. However, South's increased bargaining power makes individual 
donors less likely to participate — a possibility excluded by construction in Gatti et al.'s (2011) two-player game. Our model shows that a worse outside option for the recipient may make it better off because donors are more willing to participate when the multilateral institution they form has bargaining power. Our new contribution lies in highlighting the importance of the strategic interaction between participation and bargaining for multilateral environmental cooperation.

\section{Model}

The game we consider is played by $i=1, \ldots, n$ donors and a single recipient. We leave the analysis with multiple recipients for future research. Allowing recipients to join forces to bargain jointly with a multilateral institution (Caparrós and Péreau, 2013) or considering competition among recipients may qualify our findings in an interesting way. For project finance, however, focusing on one recipient is warranted. If a multilateral institution is to finance the installation of a hydroelectric dam project in China, for example, no recipient country other than China is directly involved in the negotiations. This direct interaction between the funding institution and a single recipient country is standard in environmental project finance. For example, this is the procedure used in the Global Environment Facility, which disbursed about US\$2.3 billion during its fourth replenishment period, 2006-2012.

Each donor can join a multilateral institution for funding a project in the recipient country. The multilateral institution offers a side payment to the recipient, and the recipient accepts or rejects. This interaction is modeled as a standard Nash (1950) bargaining game. More complex bargaining models are unnecessary because donor participation only depends on the expected bargaining payoff in the second stage. Since the Nash approach allows us to directly relate bargaining power to the relative strength of outside options, the results depend only on the key independent variable of interest, and this allows an analytically clean solution. Moreover, the results from the Nash analysis are identical to those from a non-cooperative Rubinstein (1982) bargaining game, as proven in the online appendix.

Successful project implementation produces global public goods that benefit the donors and the recipient. These benefits are modeled as the avoidance of a negative externality, such as damages from climate change of biodiversity loss. This means that whenever the project is implemented, some negative externalities are avoided. 
Additionally, successful projects may produce "club goods" (Conybeare, 1984; Cornes and Sandler, 1986; Buchanan, 1965) that produce value for the donors and the recipient but not for outsiders. For example, a renewable energy project could produce global public goods (climate mitigation, technological development) and club goods (improved local air quality, employment and export opportunities). Thus, the funding problem is one of "impure public goods" (Finus and Rübbelke, 2013). The donors and the recipient ascribe enough value to the provision of the public and club goods so that bargaining is feasible. Technically, the sum of payoffs from bargaining between the multilateral institution and the recipient must exceed the total value of the outside options. This stark assumption is analytically useful.

The sequence of the moves is the following:

1. Each donor $i=1, \ldots, n$ decides on participating in the multilateral institution, $P_{i} \in\{0,1\}$;

2. The multilateral institution plays a Nash bargaining game with the recipient. Specifically, the multilateral institution and the recipient simultaneously demand shares $s_{I}+s_{R} \in[0,1]$ of the total value of the project. If $s_{I}, s_{R} \leq 1$, so that the sought distribution of gains is feasible, the project is implemented; otherwise, the project is not implemented and the donors and the recipient obtain their payoffs from their outside options.

The first part of the model resembles Carraro and Siniscalco's (1993) and Barrett's (2001) characterization of how international agreements are formed. All donors can join the multilateral institution, and the multilateral institution then acts to maximize the collective payoff to its members. The second part captures the bargaining aspect.

In the second stage of the model, the formed institution and the recipient simultaneously demand shares $s_{I}, s_{R} \in[0,1]$ of the total value of the project. If these shares add up to 1 or less, the project is implemented, and the total value of the project is distributed according to the proposed bargaining shares. Otherwise, project implementation fails. In this case of disagreement, the global negative externality in focus is not eradicated. Both the donors and the recipient suffer from this externality and realize losses which are identical to their outside options.

Under disagreement, the payoffs are therefore the following. First, each donor $i$ pays a cost $D>0$ in damages. Second, the recipient's payoff under disagreement is $R$, without any assumption about the 
relative size of $D$ and $R$. To reflect the possibility that recipients may lose from project implementation without side payments, we allow $R$ to be positive or negative. To illustrate, consider the REDD+ program to reduce emissions from deforestation. Clearing off woodlands creates immediate revenues to the recipient, and donors may have to offer compensation. While we do not constrain $R$, it must be true that unilateral public good provision must be prohibitively costly as otherwise multilateral assistance would not be needed to cover the incremental cost.

In the Nash bargaining equilibrium, the multilateral institution and the recipient choose their optimal shares $s_{I}^{*}$ and $s_{R}^{*}$ such that they maximize their payoffs, avoiding bargaining failure. While this approach downplays bargaining failure, it does not imply that our model would always produce a fully cooperative solution in which all $n$ donors participate. Since the participation decision is endogenous, it allows inefficiency at the participation stage. ${ }^{3}$

The assumption of donor symmetry unrealistic but simplifies the analysis. It allows us to focus on a "representative" donor's incentives, with clear theoretical results and empirical hypotheses. However, the main results would also hold in an asymmetric context. Even for asymmetric donors, changes in their bargaining power vis-à-vis the recipient would effect changes in participation decisions. Unfortunately, it would be difficult to derive clear comparative statics.

The parameter $D$ reflects donors' valuation of global public goods; the parameter $R$ reflects the recipient's valuation. For example, $D$ could increase with the donors' ecological vulnerability to climate change (Sprinz and Vaahtoranta, 1994). Similarly, $R$ could increase in the recipient's vulnerability. The more countries would suffer from climate change, the more they would value the global public good of climate mitigation. Adaptive capacity could also be included.

In the case of agreement, the project is implemented but the multilateral institution and the recipient must bargain for the share of the benefits. The project is assumed to produce two different benefits. First, no donor or outsider has to pay the cost $D$, and the recipient does not have to pay the cost $R$. Thus, the negative externality in the status quo disappears due to project implementation. The benefit of avoiding costs, $D$, accrues to both participants and free riders.

Additionally, the project produces club goods worth $\alpha V$, where $\alpha>0$ is a coefficient used for the

\footnotetext{
${ }^{3}$ In an extension that covers global positive externalities from the project, we show that our main results hold even if public good provision is inefficient because of non-cooperative participation. These results are provided in the online appendix.
} 
comparative statics. As $\alpha$ increases, the availability of club goods increases. We allow $V$ to acquire negative values. Project implementation is costly, so it is possible that the net value of the club goods is negative. All this simply goes to testify to the generality of the model.

The availability of club goods depends on the number of donors, with $V=V(K)$. It is assumed that $V$ is an increasing and strictly concave function, so that the availability of club goods increases with the number of donors. This reflects economies of scale at a decreasing rate (Abbott and Snidal, 1998). As the number of donors increases, the project in focus can be implemented more effectively. Each donor may have different resources and expertise, so increasing the number of donors creates more surplus. For example, consider climate change mitigation. As the number of donors increases, they can transfer a wider variety of advanced technologies to recipient countries. This creates economic opportunities that constitute club goods.

The surplus to be distributed between the multilateral institution and the recipient is $\alpha V(K)$, where $K$ is the number of participants. All donors who do not join the initiative obtain a zero payoff: the project avoids the damage $D$ but outsiders do not obtain any club goods. Since the donors are symmetric, it is natural to assume that the multilateral institution's share of the project benefits is distributed evenly across the participating donors: each donor obtains the same payoff.

The negative externality is eradicated regardless of the number of donors. For example, consider the establishment of a forest conservation zone in Latin America. Forest conservation saves biodiversity from destruction and reduces carbon dioxide emissions. As long as a minimal number of donors join, so that a natural habitat can be conserved, this project need not be expanded beyond the geographic limits of the natural habitat. In some cases, it would be more plausible to assume that the negative externality is continuous. As the number of donors increases, outsiders' payoffs also increase. Intuitively, it seems plausible that this could induce free riding, but we show in the online appendix that the simplifying assumption is analytically innocuous. The online appendix also contains a number of other extensions of the basic model.

\section{Equilibrium}

The appropriate solution concept is the subgame-perfect Nash equilibrium. We find the largest number of donors that can participate in the multilateral institution. Given the assumption of increasing club goods 
$\alpha V(K)$, this is the welfare-maximizing equilibrium. Formally, an equilibrium comprises of strategies for the Nash bargaining game and an equilibrium number of participating donors, $K^{*} .{ }^{4}$ We provide a full analytical solution for the Nash bargaining game in the mathematical appendix.

In principle, equilibria could exist such that the project is not implemented. For example, an equilibrium could exist such that no donor joins. Therefore, the project would not be implemented. Since we are interested in bargaining, our focus is on the distribution of gains assuming that some number of donors $K^{*}>$ 0 join the multilateral institution and the project is funded. Through the remainder of the article, we therefore assume that $\alpha V(K)>-K D-R$ for all $K \neq 0$. This condition suffices to ensure that a multilateral institution with $K$ donors can be formed and that bargaining payoffs are the primary determinant of donor participation. In the mathematical appendix, we examine the consequences of relaxing this assumption, so that conventional "linchpin equilibria" (Barrett, 2001), whereby the number of participating donors is such that any given donor's exit would cause the project to fail, can exist.

In equilibrium, the Nash bargaining solution requires the surplus to be split equally after accounting for the outside option. ${ }^{5}$ Therefore, the recipient's payoff is

$$
-R+\frac{1}{2}(\alpha V(K)+K D+R)
$$

Intuitively, the recipient obtains the value of its "outside option" $-R$ and $\frac{1}{2}$ of the surplus available from bargaining, given by $\alpha V(K)+K D+R$. This payoff clearly decreases as the recipient's vulnerability to the negative externality, $R$, increases. The payoff increases as the availability of club goods $\alpha V(K)$ or the number of participating donors $K$ increases. The payoff also increases if each donor's vulnerability to the negative externality, $D$, increases. In sum, the recipient's relative bargaining power depends on the strength of its outside option relative to the multilateral institution's outside option.

\footnotetext{
${ }^{4}$ As the recipient's bargaining payoff strictly dominates the payoff from not bargaining, the recipient always enters the bargaining stage. Therefore, we need not consider the possibility of a recipient's abstention. Thus, strategies for the bargaining game together with the number of participating donors $K^{*}$ do indeed fully characterize an equilibrium.

${ }^{5}$ The 50-50 distribution of the surplus is innocuous because each side's equilibrium payoff depends on outside options. All results hold even if the generalized Nash bargaining solution is used, so that unequal splits are allowed. In standard bargaining theory, unequal splits could be derived from asymmetric discount factors in a non-cooperative Rubinstein (1982) bargaining model (Binmore, Rubinstein, and Wolinsky, 1986).
} 
The multilateral institution's collective payoff is

$$
-K D+\frac{1}{2}(\alpha V(K)+K D+R)
$$

Again, the payoff is a sum of the multilateral institution's collective outside option $-K D$ and its share of the surplus available from bargaining with the recipient, $\frac{1}{2}(\alpha V(K)+K D+R)$. The equilibrium payoff decreases as the donors' collective vulnerability to the negative externality, $K D$, increases. The payoff is increasing in the availability of club goods and increasing in the recipient's vulnerability to the negative externality, $R$. Each donor obtains this payoff divided by $K$.

Consider now the strategically prior participation stage. Since the project is always implemented in equilibrium, an outsider obtains a payoff of zero: the negative externality is eradicated but the free rider obviously cannot enjoy the club goods. In contrast, each member of the multilateral institution obtains a payoff of

$$
-D+\frac{1}{2 K}(\alpha V(K)+K D+R)
$$

In equilibrium, it must be that no member is willing to leave the coalition (internal stability) and no outsider is willing to join (external stability).

This induces the following equilibrium condition:

$$
\frac{1}{2 K}(-K D+\alpha V(K)+R) \geq 0 \geq \frac{1}{2(K+1)}(-(K+1) D+\alpha V(K+1)+R) .
$$

The first inequality ensures internal stability. Each member's payoff from participation in bargaining must be higher than the payoff she could receive from free riding. No member has an incentive to leave the coalition. The coalition is externally stable, in contrast, if no country $i$ has an incentive to enter the coalition. This requires that each outsider's payoff is higher than the payoff she would obtain from joining the multilateral institution. The second inequality captures these incentives.

Since $\frac{1}{2 K}$ and $\frac{1}{2(K+1)}$ are positive numbers, this condition simplifies to

$$
-K D+\alpha V(K)+R \geq 0 \geq-(K+1) D+\alpha V(K+1)+R
$$


Intuitively, it suffices to examine whether the collective payoff to the multilateral institution is positive or negative. Whenever it is positive (negative), the share each member receives is also positive (negative). With $V$ increasing and strictly concave, a unique equilibrium $K^{*}$ exists.

\section{Empirical Implications}

We examine variation in the equilibrium number of participants and different players' payoffs. We do so in light of the donors' avoided damages $D$, the recipient's avoided damages $R$, and the availability of club goods, $\alpha V$.

Begin with the value of the public good to donors, $D$. Differentiating equation (2) with respect to $D$ shows that the donors' bargaining power decreases due to weaker outside options. In equation (5), which captures the donor participation constraint, it follows that donor participation must decrease. In other words, as the donors' avoided damage increases, the equilibrium number of participants must decrease.

Proposition 1 (donors' avoided damages). As each donor's valuation of the avoided damage D increases, the equilibrium number of participants decreases. The increase in D has an ambiguous effect on the participating donors' and the recipient's payoff. Global welfare decreases.

Suppose that each donor's avoided damage $D$ increases slightly. If the number of participants $K$ remained unchanged, the multilateral institution's outside option in Nash bargaining would become worse, and therefore the recipient's bargaining power would increase. Thus, the multilateral institution would have to offer a larger payment for project implementation.

Putative donors now have less incentive to join the multilateral institution, and the number of participants decreases. In turn, this reduces the recipient's bargaining power because a multilateral institution with $K-1$ members ascribes less value to global public goods than an institution with $K$ members. If the multilateral institution values the global public good less, the recipient can extract fewer rents from bargaining. The effects on the donors' bargaining payoffs are ambiguous because they depend on the size of the loss in reduced club good provision relative to the multilateral institution's improved outside option with $K-1$ members. If the multilateral institution's bargaining position strengthens such that this effect compensates for the loss in club goods, the donors are better off with a smaller coalition of size $K-1$. If the opposite 
holds, donors' payoffs reduce with increases in $D$.

Why does global welfare - the sum of the recipient's, the multilateral institution's, and the free riders' payoffs - decrease $?^{6}$ The reason is the reduced production of club goods. The project is implemented even with fewer participating donors, but fewer donors produce fewer club goods. While the donors may win due to increased bargaining power, global welfare must decrease. The global optimum would be for all donors to participate, so that the production of club goods could be maximized, but this is only possible in rare circumstances. Indeed, as the avoided damage $D$ increases, the gap between equilibrium and full participation widens as free riding becomes more attractive.

In conventional cooperation problems (Barrett, 2001), participation is an issue because large coalitions are not internally stable. In our model, the logic is quite different. Even though countries' participation decisions do not influence the probability of project implementation, their participation does influence the multilateral institution's bargaining power vis-à-vis the recipient. As donors' valuation of the public good increases, this negative bargaining effect is amplified. Therefore, equilibrium participation must decrease.

Empirically, the news about participation in multilateral funding for global public goods is worrisome. Donors have incentives to remain outsiders, even if many club goods are readily available. The problem would be worse if some outsiders, such as other recipients, would also benefit from project implementation. For example, one could assume that some third countries outside the model would enjoy positive spillovers from club good production, denoted by $\beta V(K)$, where $\beta>0$. As the donors' valuation of the global public good increases, fewer of them join the multilateral institution, and therefore $\beta V(K)$ decreases as well.

Since the recipient also values the global public good, one may conjecture that an increase in the recipient's valuation $R$ should also reduce participation. This conjecture is invalid. Instead, differentiation of equation (2) with respect to $R$ means that donors' bargaining payoff increases due to the recipient's weaker outside options. In turn, this increases the number of donors who are willing to participate.

Proposition 2 (recipient's avoided damages). As the recipient's valuation of the avoided damage $R$ increases, the equilibrium number of participants increases. The increase in $R$ has an ambiguous effect on the participating donors' and the recipient's equilibrium payoff. Global welfare increases.

\footnotetext{
${ }^{6}$ Since free riders' payoffs are zero, global welfare results from adding up equations (1) and (2). This is identical to the size of the provided club goods $\alpha V(K)$.
} 
Suppose the recipient's avoided damage $R$ increases. This means that the recipient's disagreement point in the bargaining game becomes worse. The recipient stands to lose more in the case of bargaining failure if its vulnerability to the negative externality is increased. Consequently, the multilateral institution's share of the divisible surplus increases. Each outside donor now has more incentives to join the multilateral institution, because the donor expects more rents from bargaining. Since more participation increases the availability of club goods from $\alpha V(K)$ to $\alpha V(K+1)$, global welfare increases.

This result turns the conventional wisdom on participation on its head. Although the donors' avoided damages $D$ reduce participation, this is decidedly not true of the recipient. To understand multilateral funding of global public goods in a North-South context, it is essential to distinguish between the avoidance of negative externalities in the global North and South. When donors suffer, their participation is difficult to induce. But when recipients suffer, donors have stronger incentives to participate. Any changes that weaken the recipient's outside option produce an increase in donors' bargaining power, and therefore their incentive to engage in bargaining increases.

This result is good news for multilateral funding of global public goods. As long as the recipients also value these global public goods, donors have incentives to join multilateral funding institutions. The essential assumption for this result is that donors and recipients are able to implement side payments and issue linkages in a fashion that allows the realizing of joint gains. Given this, it turns out that a recipient may actually benefit from reduced bargaining power. When the recipient's bargaining power decreases due to changed outside options, either because its avoided damages $R$ decrease or the donors' collective valuation of the avoided damage $N D$ increases, more donors join the multilateral institution. If this increase produces enough club goods, so that $\alpha V(K+1)-\alpha V(K)$ is large, then increased equilibrium participation allows both the donors and the recipient to increase their payoffs.

These two propositions are readily testable with data on multilateral finance for global public goods. To illustrate, consider the case of environmental aid. The AidData project has collected data on hundreds of thousands of environmental aid projects in different recipient countries (Hicks et al., 2008). ${ }^{7}$ Our model generates three predictions for participation and cost distribution.

First, the model predicts that donors have particularly strong incentives to fund projects in vulnerable

\footnotetext{
${ }^{7}$ See http: //www. aiddata.org/home/index. Accessed on October 11, 2011.
} 
recipient countries with little bargaining power. Vulnerability can be partially measured using data on environmental conditions. As Roberts and Parks (2007) note, however, environmental vulnerability depends on both the physical characteristics of the country and the level of economic development. In practice, the recipient's vulnerability also depends on the opportunity cost of environmental protection, such as the value of hardwood from felling a rainforest (Barrett, 1994a). This hypothesis can be tested by examining whether large multilateral institutions more readily fund projects in vulnerable recipient countries. The flip side of this is that bilateral and minilateral projects are more likely implemented in less vulnerable recipient countries. Testing for positive correlations between the number of donors involved in particular projects and recipient countries' vulnerability could provide empirical leverage on this hypothesis. ${ }^{8}$

Second, the model predicts that the donors' share of total project cost should decrease as the vulnerability of recipient countries increases. We expect to see donors reap large gains from projects implemented in vulnerable recipient countries. This hypothesis can be tested by examining the relationship between recipient vulnerability and donors' funding share in the data. Following the lead of Hicks et al. (2008), this hypothesis could also be tested by examining whether ecological and other forms of vulnerability influence a recipient's "project portfolio." Compared to highly vulnerable countries, do less vulnerable recipients secure more environmental aid for projects that benefit them the most then?

Finally, the most counterintuitive predictions from the model are that as donor vulnerability increases or recipient dependence on the project increases, the number of participating donors should decrease. AidData coding on project type, such as the distribution between global environmental benefits (green aid) and local environmental benefits (brown aid), provides an opportunity to test this hypothesis. While a full quantitative analysis is beyond the scope of this study, Figure 1 shows patterns consistent with our argument. As concerns about climate change have grown and the bargaining power of emerging developing economies have grown, donors have reacted by shifting their focus from multilateral to bilateral aid provision.

This is consistent with our hypotheses, which predict that participation in multilateral institutions should decrease given the structural changes outlined above. As donors now increasingly emphasize bilateral at the expense of multilateral aid, such a shift is indeed occurring. Consistent with our bargaining theory at a time when the recipients are growing increasingly powerful, donors prefer to avoid channeling funds through

\footnotetext{
${ }^{8}$ It is important to control for other factors, such as institutional capacity building, that may require more contributions from donors.
} 
multilateral institutions and $a d$ hoc funds. Moreover, there is no such effect for projects that produce mostly local benefits (brown aid). In recent years, bilateral green environmental aid has grown rapidly compared to multilateral green aid. Consistent with our theory, it seems that donor countries are no longer willing to participate in the provision of global public goods through multilateral institutions.

[Figure 1 about here.]

Let us finally examine the role of club goods. Examining equation (2), the donors' collective payoff must increase as the abundance of club goods increases. Therefore, participation must also increase, as an examination of equation (5) shows. This benefits the recipient, as increased donor participation further increases the availability of club goods.

Proposition 3 (availability of club goods). Suppose the availability of club goods $\alpha$ increases. The equilibrium number of participants increases. The increase in $\alpha$ has an ambiguous (positive) effect on the participating donors' (recipient's) equilibrium payoff. Global welfare increases.

As the availability of club goods increases, the equilibrium number of participants increases. Given that club goods are not available to outsiders, donors' incentives to participate also increase. This is obviously beneficial for the recipient because (i) the value of the project increases by $\alpha V(K+1)-\alpha V(K)$ and (ii) the donors' bargaining power decreases due to a weaker outside option $-(K+1) D$ instead of $-K D$.

This result only requires an increase in the overall availability of club goods. Whether these club goods become available in the donor or recipient countries is not relevant because this does not influence the bargaining outcome. This claim is important because it suggests that the source of the club goods is a relatively unimportant factor in explaining donor participation in multilateral funding institutions. In the case of renewable energy projects, for example, the availability of ancillary benefits should increase participation regardless of whether they initially accrue to donors or recipients. For example, if Germany funds a solar energy project in Morocco, an increase in the availability of profits for German solar technology manufacturers and an increase in the value of reduced air pollution in Morocco should have broadly similar effects.

Since availability of club goods increases donor participation, large multilateral institutions should be particularly willing to fund projects that create opportunities for technology exports from donor countries, employment in recipient countries, and so on. The AidData project codes different environmental and other 
aid projects by sector. One could distinguish between projects that require major capital investments, such as renewable energy and water sanitation, versus projects that do not, such as biodiversity conservation. Large capital investments should promote donor participation.

The equilibrium determinants of participation are shown in Figure 2(a). The top-left panel examines equilibrium participation $K^{*}$ and illustrates the pronounced negative impact on coalition size with increasing levels of donor valuation $D$. As the multilateral institution's outside option becomes worse, large coalitions are no longer internally stable and donors leave the bargaining table. For multilateral institutions of large size, even small increases in $D$ induce a drop in the number of participating donors. While small increases in $D$ may be negligible at the individual level, the institution's collective outside option weakens $K$ times as much. Hence, many putative donors exit the coalition because the expected bargaining payoffs are dwarfed by the returns from free riding.

[Figure 2 about here.]

The paradox of participation (Barrett, 1994b), which states that large coalitions can only be sustained when returns to cooperation are small, again holds. However, this is so for very different reasons. Increasing benefits due to higher valuations of the project undermine the multilateral institution's bargaining position and turn participation into an unattractive choice. This effect is counteracted by rising valuations $R$ for the recipient. In line with our argument in Proposition 2, a weakened recipient's outside option $-R$ confers additional bargaining leverage to the multilateral institution.

We now graphically illustrate the payoffs to the players. For the recipient, an increase in the donor's valuation $D$ and a corresponding decrease in the equilibrium coalition size $K^{*}$ have unambiguously negative consequences. The recipient's payoffs must diminish because of two jointly negative effects. First, the provision of the club good $\alpha V(K)$ is reduced as fewer donors join the multilateral institution. Second, the drop in the number of participating donors improves the multilateral institution's bargaining position vis-à-vis the recipient. Therefore, the recipient must be worse off for any increase in $D$.

Figure 2(b) above shows that an increase in the recipient's valuation $R$ yields positive returns for her. Surprisingly, a weakened outside option is advantageous for the recipient. The ambiguous effect identified in our second proposition turns out to be strictly positive for the chosen functional form in the plot. ${ }^{9}$ Sub-

\footnotetext{
${ }^{9}$ Specifically, we choose a square root function for the generation of club goods, such that $V(K)=\sqrt{K}$. Also, we set the
} 
stantively, this illustration carries home the point that a recipient benefits from higher project valuations if these induce enough donor countries to join the multilateral institution. As we show in the mathematical appendix, this result prevails as long as the recipient's loss in its own bargaining position is outweighed by the gains from higher club good provision and the benefits from a deteriorated outside option for the multilateral institution due to increased participation $K^{*}$. From a policy perspective, this is an interesting finding as it foreshadows the possibility for Pareto-improving bargaining over global public goods.

Increasing project valuations in recipient countries are also beneficial for the multilateral institution as a whole. This becomes clear from the lower-left plot 2(c). Again, this monotonically positive effect is conditional on the institution's loss in bargaining power to be smaller than the sum of gains from club goods and from a worsened recipient's bargaining position. It is evident from the two sufficient conditions that win-win bargaining is more likely when the benefits from club goods are expected to be large. This can either be the case due to high availability of $\alpha V(K)$ or due to an expedient ramping up in coalition size.

Participation often matters more than a country's bargaining position. As soon as club good effects that heavily rely on the number of participants trump the bargaining effects, countries' payoffs are increasing. This does not undermine the importance of bargaining, however, as donors join the multilateral institution with the expected bargaining outcome in mind.

This connection is also reflected in the bargaining payoffs for a single participating donor, as depicted in Figure 2(d). The payoff for an individual donor country depends on the number of participating countries in two ways. First, the number of participating donors determines the outside option of the multilateral institution and thereby its bargaining position. Second, participation $K^{*}$ is inversely related to individual payoffs as the institution's returns are split equally among all contributors. Therefore, we find that even though the multilateral institution's payoff is decreasing in $D$, this must not be the case for an individual donor's payoff. Clearly, the institution receives gradually lower returns as the outside option deteriorates, but these returns must also be shared with fewer participating donors. Therefore, a donor can be better off in an equilibrium with high avoided damages from project implementation but few contributors compared to a low benefit, high participation equilibrium. This positive payoff effect vanishes, however, as the recipient country's bargaining position $R$ improves.

availability parameter $\alpha$ equal to one, i.e., $\alpha=1$. 
By Propositions 1 and 3, we expect donors to benefit from multilateral funding arrangements that maximize their bargaining position vis-à-vis recipients and produce club goods, such as economic profits for contractors. One reason why Ecuador's promise to save the Yasuní National Park may have failed is the lack of club good provision. Since the idea was to simply keep the rainforest as it was, there were no benefits to participating donors. No wonder, then, that pledges were not forthcoming.

\section{Conclusion}

Funding environmental protection through multilateral institutions is not easy. First, donor countries decide if they are willing to join a multilateral institution to fund the environmental projects. Upon participation, they bargain with a recipient country over the distribution of gains from project implementation. The participation decision depends on the expectation about bargaining benefits, while these benefits are affected by the number of participants in the funding coalition. Even though the literature reviewed above has studied the participation problem and donor recipient bargaining, we are not aware of any research that brings these two together.

We have examined participation and bargaining over global public goods in a game-theoretic model. Our key insight is that while the paradox of participation applies to donor countries, it fails for recipient countries. In line with previous research, we find that an increase in donor countries' valuations for global public goods reduces the donors' willingness to participate. The more donors need to avoid negative externalities, the weaker is the multilateral institution's bargaining position. This loss in bargaining power reduces expected benefits from bargaining, so participation decreases.

For a recipient country, an increase in the valuation of the global public good also produces a worse bargaining position. However, more donors join the coalition. If this participation effect is large enough to generate a sufficient amount of club goods for the bargaining parties, the recipient actually benefits from the weakened outside option. A sharp focus on bargaining incentives and club goods forces scholars to qualify the standard findings in the participation literature (Barrett, 1994b; Hoel and Schneider, 1997). 


\section{Mathematical Appendix: Nash Bargaining}

As described in the main text, once a multilateral institution is formed, we assume the multilateral institution and the recipient to play a Nash (1950) bargaining game. In a Nash bargaining game, both the multilateral institution $I$ and the the recipient $R$ simultaneously propose a share $s_{i} \in[0,1]$ with $i=I, R$. If the proposed shares sum to one or are smaller, bargaining is successful, whereas bargaining fails if $s_{I}+s_{R}>1$. In this latter case both players realize their disagreement points, which are $-K D$ and $-R$ for the the multilateral institution and the recipient, respectively. If cooperation is achieved, damages are avoided and benefits from club goods $\alpha V(K)$ also materialize. Any allocation such that $s_{I}+s_{R}=1$ is a Nash equilibrium on the Pareto frontier.

Finding the Nash bargaining solution requires the maximization of the Nash product $\left(U^{I}-U_{0}^{I}\right)\left(U^{R}-\right.$ $\left.U_{0}^{R}\right)$, where $U^{I}$ and $U^{R}$ are utility levels from successful bargaining, while $U_{0}^{I}$ and $U_{0}^{R}$ are utility levels at the disagreement points. Plugging disagreement points into the Nash product equation and noting that $U^{R}=-U^{I}+\alpha V(K)$ needs to hold because $s_{I}+s_{R}=1$, we face the following maximization problem:

$$
\max _{U^{I}}\left(U^{I}+K D\right)\left(-U^{I}+\alpha V(K)+R\right)
$$

where the identity $U^{R}=-U^{I}+\alpha V(K)$ holds as Nash bargaining is conceptualized as a zero-sum game on the Pareto frontier. For successful bargaining, the Pareto frontier is pushed outwards due to the additional utility from the club goods $\alpha V(K)$.

Multiplying out and taking the first-order derivative with respect to $U^{I}$ yields

$$
\alpha V(K)+R-K D=2 U^{I}
$$

as first-order condition. This can be re-written as $U^{I}=-K D+\frac{1}{2}(\alpha V(K)+K D+R)$, which is identical to what we have in equation (2). Due to symmetry of the game, we get $U^{R}=-R+\frac{1}{2}(\alpha V(K)+K D+R)$ for the recipient. The payoff to both bargaining parties is thus the difference between half of the added value from successful bargaining, $\alpha V(K)+K D+R$, and their respective disagreement point $-K D$ and $-R$. Note that we suppose that the multilateral institution's utility-maximizing payoff is allocated equally across 
its member states. Hence, we divide $U^{I}$ by the number of $K$ members to get individual donor payoffs.

\section{Mathematical Appendix: Proofs}

Proof of Proposition 1. Consider the claim that the equilibrium number of participating donors must (weakly) decrease. Suppose each donor's valuation of the global public good $D$ is replaced by a higher valuation level $\bar{D}$, so that $\bar{D}>D$. As each donor's valuation of the global public good increases, the internal stability condition in equation (5) is more difficult to satisfy because $-K D+\alpha V(K)+R$ is decreasing in $D$. With $V(K)$ increasing and strictly concave, this means that the number of participating donors must decrease for the internal stability condition to hold. The external stability continues to hold since $\bar{D}>D$.

Consider now the recipient's payoff. To show that the effect of an increase in $D$ is ambiguous we need to consider two cases: one in which the equilibrium coalition size, $K^{*}$, remains unchanged and one in which coalition size strictly decreases to $\underline{K}$, where $\underline{K}<K^{*}$.

For the first case, it is easy to show that the recipient benefits from an increase of the donors' valuation from $D$ to $\bar{D}$. As $K^{*}$ is constant for this case, the club good benefits, $\alpha V(K)$, remain the same, but the multilateral institution's outside option weakens. With fixed $K^{*}, K^{*} \bar{D}>K^{*} D$ needs to hold as $\bar{D}>D$ is given by definition. Therefore, the recipient benefits from increases in $D$ whenever $K^{*}$ does not change.

For the second case for which equilibrium coalition size decreases to $\underline{K}$, recipient payoffs will be negative. With $\underline{K}$, it is evident that $\alpha V(\underline{K})<\alpha V\left(K^{*}\right)$ as $\alpha V(K)$ is increasing in $K$. Hence, benefits from club goods, $\alpha V(K)$, must decrease. As club goods decrease, the new stable coalition $\underline{K}$ must be smaller than a coalition for which the increase in the donors' project valuation to $\bar{D}$ and the decrease in coalition size would just cancel out. Specifically, it must be the case that $\underline{K} \bar{D}<K^{*} D$ for the left inequality in equation 4 to hold. Under such conditions both $\underline{K} \bar{D}$ and $\alpha V(\underline{K})$ are smaller than in the original equilibrium. This reduces the recipient's payoff, as can be seen in expression (1).

In one case, the recipient's payoff increases. In the other case, the recipient's payoff decreases. Together, these imply that the effect of increasing $D$ on the recipient's payoff is ambiguous.

The effect on donors' payoffs is ambiguous as well. For them, the payoffs in the new equilibrium with 
fewer coalition members $\underline{K}$ are higher than in the old equilibrium with $K^{*}$ members if

$$
K^{*} D-\underline{K} \bar{D}>\alpha\left(V\left(K^{*}\right)-V(\underline{K})\right)
$$

holds. To understand this result it is important that an increase in $D$ weakens the outside option of each potential donor country $i$. But as more and more donors leave the multilateral institution, the outside option of the institution as a whole improves as the valuations of each single member increase, but the number of coalition members reduces. Mathematically, we have $\underline{K} \bar{D}<K^{*} D$. If this effect from an improved outside option outweighs the loss in club goods, the donor countries are better off. If the opposite holds, they are worse off. Therefore, the effect of an increase in $D$ on donors' payoffs is ambiguous.

Let global welfare $\Pi$ be defined as the sum of the payoffs of the donors, the recipient, and the $n-K$ free riders. This yields

$$
\Pi=-K D+\frac{1}{2}(\alpha V(K)+K D+R)-R+\frac{1}{2}(\alpha V(K)+K D+R)+(n-K) \cdot 0=\alpha V(K),
$$

which trivially shows that global welfare is decreasing with decreasing $K$. This concludes the proof.

Proof of Proposition 2. With a rise in the recipient's valuation of the global public good $R$, the external stability condition in equation (5) is more difficult to meet because $-(K+1) D+\alpha V(K+1)+R$ is increasing in $R$. The collective payoff must decrease, so that the condition can still hold. Therefore, the equilibrium number of participating donors $K^{*}$ must weakly increase. Note again that with an increasing recipient valuation $R$, no coalition member has an incentive to leave the coalition. Internal stability is unproblematic for higher values of $R$.

Let $\bar{R}$ denote the higher valuation level and let $\bar{K}$ be the increased coalition size caused by an increase in $R$. Then the multilateral institution is better off in the larger equilibrium with $\bar{K}$ if

$$
\alpha\left(V(\bar{K})-V\left(K^{*}\right)\right)+(\bar{R}-R)>D\left(\bar{K}-K^{*}\right)
$$

holds. This condition may or may not hold, so an increase in $R$ has an ambiguous effect on donors' payoffs. Applying the same logic to the recipient's payoffs for coalition sizes of $\bar{K}$ and $K^{*}$ allows us to derive 
the following condition under which the larger coalition confers higher payoffs. If

$$
D\left(\bar{K}-K^{*}\right)+\alpha\left(V\left(\bar{K}-V\left(K^{*}\right)\right)>\bar{R}-R\right.
$$

is satisfied, the recipient is better off with $\bar{K}$ coalition members even though her outside option is weakened because of the increase in $R$. If this condition is not met, the recipient does not benefit enough from increased participation in the multilateral institution. Hence, the payoff effects are ambiguous for the recipient as well as for the donor.

In equilibrium, global welfare is identical to $\alpha V(K)$. This function increases with $K$, so global welfare is increasing for increasing levels of $R$, as more outside countries have incentives to join the funding institution. This proves all the claims in Proposition 2 and concludes the proof.

Proof of Proposition 3. An increase in the availability of club goods $\alpha$ means that the external stability condition is more difficult to meet because $-(K+1) D+\alpha V(K+1)+R$ is increasing in $\alpha>1$. For this condition to hold for an increased $\alpha$, the equilibrium size of the coalition $K^{*}$ must increase. When there is more to gain from bargaining because of more available club goods $\alpha V(K)$, the incentives for donors to join the coalition increase. Internal stability holds.

Let $\bar{\alpha}$ denote the new availability level of club goods and let $\bar{K}$ be the new equilibrium coalition size. An increase in $\alpha$ has a positive impact on the donors' payoffs if

$$
\bar{\alpha} V(\bar{K})-\alpha V\left(K^{*}\right)>D\left(\bar{K}-K^{*}\right)
$$

holds. This effect is positive if the increase in benefits from club goods outweighs the losses from the multilateral institution's weakened bargaining position. With an increasing number of coalition members, the outside option is weakened for the multilateral institution. But when this negative effect is larger than the net gain in club goods, an increase in $\alpha$ results in a lower payoff for donors.

For the recipient, an increase in $\alpha$ not only increases the availability of club goods but also increases its own bargaining power relative to the multilateral institution. Both factors increase the recipient's payoff.

As global welfare is given by the club goods, $\alpha V(K)$, an increase in $\alpha$ with an associated increase in $K$ induces global welfare to increase. This concludes the proof of Proposition 3. 


\section{References}

Abbott, Kenneth W., and Duncan Snidal. 1998. "Why States Act through Formal International Organizations." Journal of Conflict Resolution 42 (1): 3-32.

Anand, P.B. 2004. "Financing the Provision of Global Public Goods." World Economy 27 (2): 215-237.

Barrett, Scott. 1994a. “The Biodiversity Supergame.” Environmental and Resource Economics 4 (1): 111122.

Barrett, Scott. 1994b. "Self-Enforcing International Environmental Agreements." Oxford Economic Papers 46 (Supplement): 878-894.

Barrett, Scott. 1997. "The Strategy of Trade Sanctions in International Environmental Agreements." Resource and Energy Economics 19 (4): 345-361.

Barrett, Scott. 2001. “International Cooperation for Sale.” European Economic Review 45 (10): 1835-1850.

Barrett, Scott. 2003. Environment and Statecraft: The Strategy of Environmental Treaty-Making. Oxford: Oxford University Press.

Barrett, Scott. 2006. "Climate Treaties and "Breakthrough" Technologies." American Economic Review (96): $22-25$.

Barrett, Scott. 2007. Why Cooperate? The Incentive to Supply Global Public Goods. Oxford: Oxford University Press.

Barrett, Scott. 2012. "Climate Treaties and Backstop Technologies." CESifo Economic Studies 58 (1): 3148.

Binmore, Ken, Ariel Rubinstein, and Asher Wolinsky. 1986. "The Nash Bargaining Solution in Economic Modelling." Rand Journal of Economics 17 (2): 176-188.

Buchanan, James M. 1965. “An Economic Theory of Clubs.” Economica 32 (125): 1-14.

Caparrós, Alejandro, and Jean-Christophe Péreau. 2013. "Forming Coalitions to Negotiate North-South Climate Agreements." Environment and Development Economics 18 (1): 69-92.

Carraro, Carlo, and Domenico Siniscalco. 1993. "Strategies for the International Protection of the Environment.” Journal of Public Economics 52 (3): 309-328.

Conybeare, John A.C. 1984. "Public Goods, Prisoners' Dilemmas and the International Political Economy." International Studies Quarterly 28 (1): 5-22.

Cornes, Richard, and Todd Sandler. 1986. The Theory of Externalities, Public Goods, and Club Goods. New York: Cambridge University Press.

de Zeeuw, Aart. 2008. "Dynamic Effects on the Stability of International Environmental Agreements." Journal of Environmental Economics and Management 55 (2): 163-174. 
Finus, Michael. 2008. "Game Theoretic Research on the Design of International Environmental Agreements: Insights, Critical Remarks, and Future Challenges." International Review of Environmental and Resource Economics 2 (1): 29-67.

Finus, Michael, Christos Kotsogiannis, and Steve McCorriston. 2013. "International Coordination on Climate Policies." Journal of Environmental Economics and Management 66 (2): 159-165.

Finus, Michael, and Dirk Rübbelke. 2013. "Public Good Provision and Ancillary Benefits: The Case of Climate Agreements." Environmental and Resource Economics (56): 211-226.

Finus, Michael, and Pedro Pintassilgo. 2012. "International Environmental Agreements Under Uncertainty: Does the Veil of Uncertainty Help?" Oxford Economic Papers 64 (4): 736-764.

Fischer, Carolyn, and Richard G. Newell. 2008. "Environmental and Technology Policies for Climate Mitigation.” Journal of Environmental Economics and Management 55 (2): 142-162.

Gatti, Rupert, Timo Goeschl, Ben Groom, and Timothy Swanson. 2011. "The Biodiversity Bargaining Problem." Environmental and Resource Economics 48 (4): 609-628.

Goeschl, Timo, and Timothy Swanson. 2002. "The Social Value of Biodiversity R\&D." Environmental and Resource Economics 22 (4): 477-504.

Hicks, Robert L., Bradley C. Parks, J. Timmons Roberts, and Michael J. Tierney. 2008. Greening Aid? Understanding the Environmental Impact of Development Assistance. New York: Oxford University Press.

Hoel, Michael. 1992. "International Environmental Conventions: The Case of Uniform Reductions of Emissions." Environmental and Resource Economics 2 (2): 141-159.

Hoel, Michael, and Aart de Zeeuw. 2010. "Can a Focus on Breakthrough Technologies Improve the Performance of International Environmental Agreements?" Environmental and Resource Economics 47 (3): 395-406.

Hoel, Michael, and Kerstin Schneider. 1997. "Incentives to Participate in an International Environmental Agreement." Environmental and Resource Economics 9 (2): 153-170.

Kaul, Inge, Isabelle Grunberg, and Marc A. Stern. 1999. Global Public Goods: International Cooperation in the 21st Century. New York: Oxford University Press.

Kolstad, Charles, and Alistair Ulph. 2008. "Learning and International Environmental Agreements." Climatic Change 89 (1-2): 125-141.

Kolstad, Charles D. 2007. "Systematic Uncertainty in Self-Enforcing International Environmental Agreements." Journal of Environmental Economics and Management 53 (1): 68-79.

Kolstad, Charles D., and Alistair Ulph. 2011. "Uncertainty, Learning and Heterogeneity in International Environmental Agreements." Environmental and Resource Economics 50 (3): 389-403.

Martin, Pamela L. 2011. "Global Governance from the Amazon: Leaving Oil Underground in Yasunií National Park, Ecuador." Global Environmental Politics (11): 22-22. 
McGinty, Matthew. 2007. "International Environmental Agreements among Asymmetric Nations." Oxford Economic Papers 59 (1): 45-62.

Na, Seong-lin, and Hyun Song Shin. 1998. "International Environmental Agreements under Uncertainty." Oxford Economic Papers 50 (2): 173-185.

Nash, John F. 1950. “The Bargaining Problem.” Econometrica 18 (2): 155-162.

Roberts, J. Timmons, and Bradley C. Parks. 2007. A Climate of Injustice: Global Inequality, North-South Politics, and Climate Policy. Cambridge: MIT Press.

Rubinstein, Ariel. 1982. "Perfect Equilibrium in a Bargaining Model." Econometrica 50 (1): 97-110.

Rubio, Santiago J., and Alistair Ulph. 2007. “An Infinite-Horizon Model of Dynamic Membership of International Environmental Agreements." Journal of Environmental Economics and Management 54 (3): 296-310.

Ruggie, John Gerard. 1992. "Multilateralism: the Anatomy of an Institution." International Organization 46 (3): 561-598.

Sandler, Todd. 2004. Global Collective Action. New York: Cambridge University Press.

Sprinz, Detlef, and Tapani Vaahtoranta. 1994. "The Interest-Based Explanation of International Environmental Policy." International Organization 48 (1): 77-105.

Ulph, Alistair. 2004. "Stable International Environmental Agreements with a Stock Pollutant, Uncertainty and Learning." Journal of Risk and Uncertainty 29 (1): 53-73.

Ulph, Alistair, and David Maddison. 1997. "Uncertainty, Learning and International Environmental Policy Coordination.” Environmental and Resource Economics 9 (4): 451-466.

Ulph, Alistair, and David Ulph. 1997. "Global Warming, Irreversibility and Learning." The Economic Journal 107 (442): 636-650.

Underdal, Arild. 1980. The Politics of International Fisheries Management: The Case of the Northeast Atlantic. Oslo: Universitetsforlaget. 


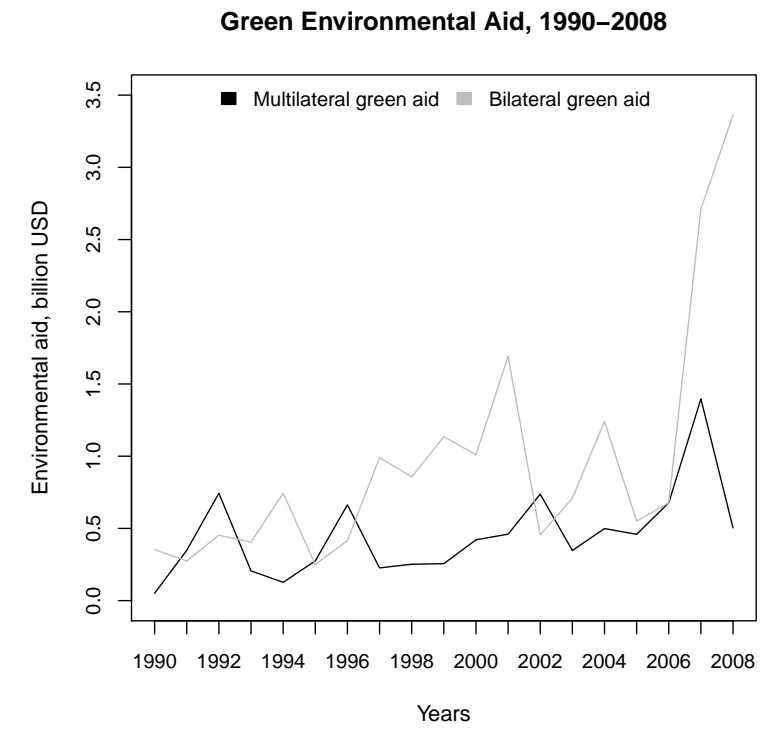

(a) Green environmental aid, 1990-2008.

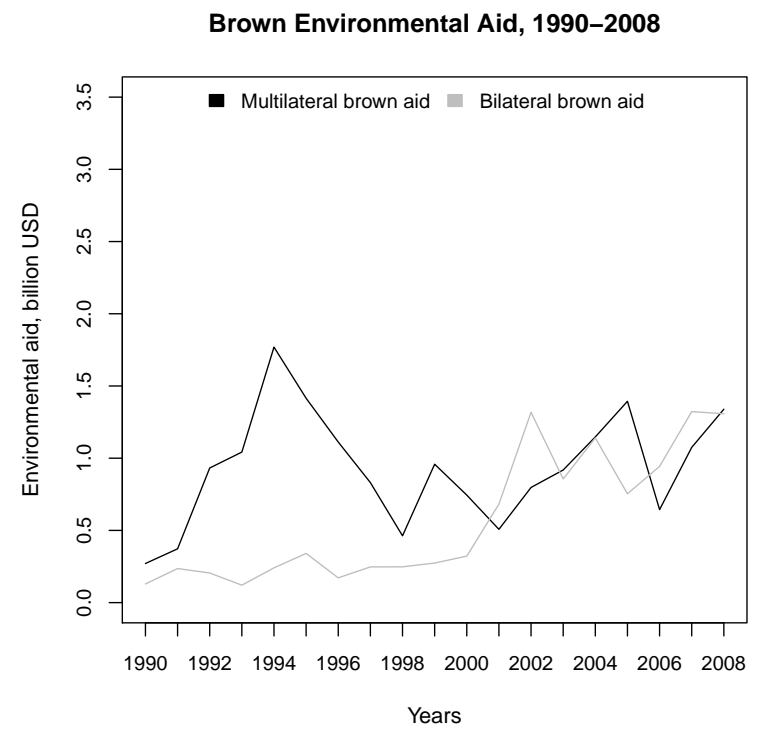

(b) Brown environmental aid, 1990-2008.

Figure 1: Green and brown environmental aid, separately for multilateral and bilateral aid, 1990-2008. In recent years, multilateral green environmental aid decreases while bilateral green aid increases. This shift towards more bilateral aid, which is only found for green but not for brown aid, is consistent with our expectations. 


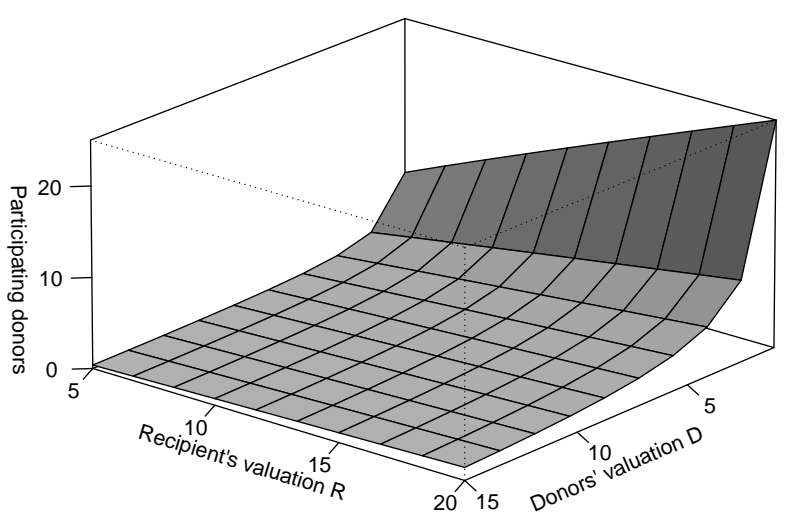

(a) Equilibrium participation $K^{*}$.

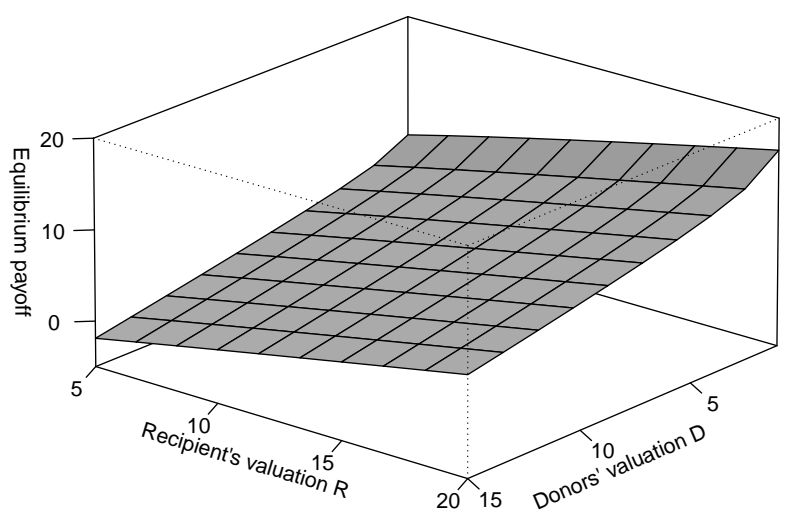

(c) Equilibrium payoffs for the multilateral institution.

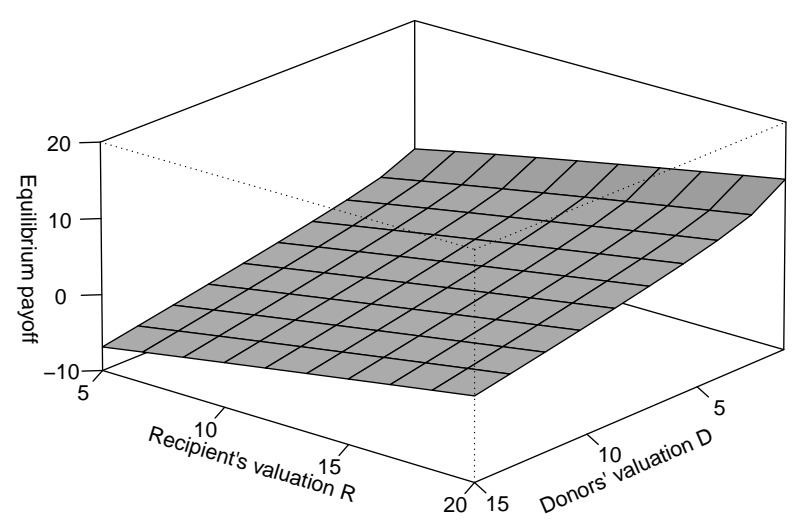

(b) Equilibrium payoffs for the recipient.

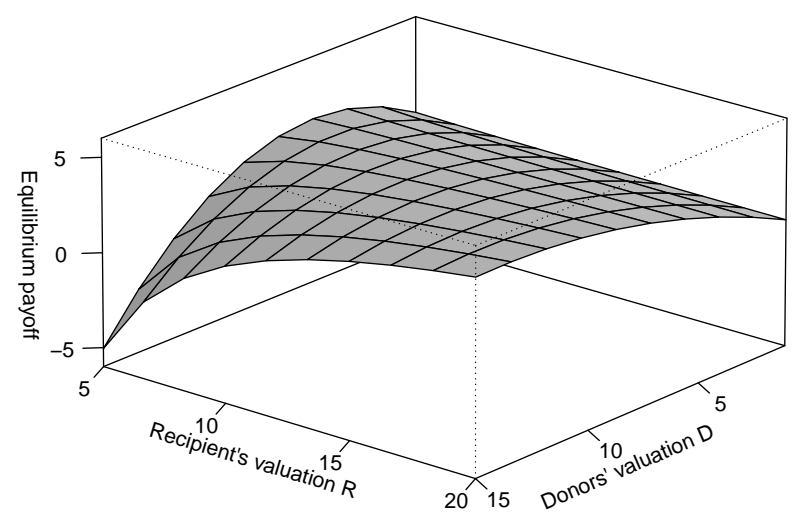

(d) Equilibrium payoffs for a single participating donor.

Figure 2: Illustration of Propositions 1 and 2. The four plots illustrate the effects of changes in the recipient's and the multilateral institution's valuations $R$ and $D$ on the equilibrium size of participation (plot 2(a)), on equilibrium payoffs for the recipient (plot 2(b)), on equilibrium payoffs for the multilateral institution (plot 2(c)), and on the equilibrium payoffs of a single participating donor country (plot 2(d)). To generate the plots as shown, we used the square root function as functional form for club good benefits, $V(K)=\sqrt{K}$ and fixed the parameter for the availability of club goods to one, $\alpha=1$. 